\title{
Determination of Selected Physicochemical Parameters and Heavy Metals in a Drilling Cutting Dump Site at Ezeogwu-Owaza, Nigeria.
}

\author{
${ }^{1}$ JOEL, O. F.; ${ }^{2}$ AMAJUOYI, C. A \\ ${ }^{1}$ Department of Petroleum and Gas Engineering, Faculty of Engineering, University of Port Harcourt, Nigeria.. \\ Ogbonna.Joel@yahoo.com; 08052276568,08037099211. \\ ${ }^{2}$ Pollution Control and Environmental Management Consultants, Port Harcourt, Nigeria. Allwellcave@yahoo.com.
}

\begin{abstract}
The work was undertaken to determine some selected physicochemical parameters and heavy metals in a drilling cutting dump site. Test results indicated that some of the heavy metals like copper, iron and calcium showed a high level of contamination in most of the plots under the study area. Iron had a value as high as $880 \mathrm{mg} / \mathrm{kg}$, copper $84 \mathrm{mg} / \mathrm{kg}$ and calcium $12560 \mathrm{mg} / \mathrm{kg}$. These values were above target values as specified by the regulatory body, Department of Petroleum Resources (DPR). Moreover, the oil and grease indicated a high level of contamination, with a concentration of up to $840 \mathrm{mg} / \mathrm{kg}$ in one of the plots. This was evident in lack of plant growth noticed in the study area as a result of depletion of NPK values below specified value by USDA Standards for plant growth. The high level of contamination of some of the physicochemical parameters and heavy metals as seen in this project underscores the need for due diligence in managing drilling cutting discharges from drilling activities. @ JASEM
\end{abstract}

Drilling fluids are used in the oil and gas industry for the drilling of bore holes and construction of oil wells. They are typically classified as either waterbased or oil-based/invert emulsions. Another class has been developed that replaces traditional oils with synthetic organic liquids designed to provide superior environmental performance. Water-based fluids contain clays, weighting agents and other specialty chemicals in the aqueous phase whereas oil-based or synthetic-based fluids contain a hydrocarbon continuous phase with an emulsified internal aqueous "brine" phase in addition to clays, weighting agents and other additives (Drilling Fluids Engineering Manual, M-I L.L.C, 1998). Such fluids fulfil a wide variety of functions in drilling operations, including maintaining pressure in the formation rocks and helping to protect and support the borehole wall, preventing collapse. They are also designed to protect permeable zones from damage while drilling, increasing rates of hydrocarbon recovery. Drilling fluids also help to cool and lubricate the drill bit and drill string and are essential for removing the excavated rock or "drill cuttings" from the borehole. Rock debris generated during drilling is carried to the surface by the drilling fluid whereupon the cuttings are removed using solids-control equipment. This aim of this procedure is to remove as much of the solid contaminants from the fluid as is economically possible before the fluid is returned to the active mud system and re-circulated back down the borehole (Drilling Fluids Engineering Manual, M-I L.L.C, 1998).

When oil-based or synthetic-based drilling fluids are used, the discharged cuttings typically have a hydrocarbon content of $10-15 \%$ along with residual salt from the internal phase and residual weighting material. While properly managed cuttings have been safely disposed for many years, untreated cuttings can have a considerable impact on the receiving environment and this has led to the development of increasingly strict disposal regulations around the world. Although the hydrocarbon portion of the drilling fluid is often viewed as the main contaminant and cause for concern, drilling fluids comprise a number of other materials that can also impact the environment. The two other main areas of concern regarding the disposal of drill cuttings are the electrical conductivity (typically the chloride content of the brine phase) and the possible heavy metal content of the waste (Growcock, 2002; Curtis, 2001). The concentrations of these materials together with the total petroleum hydrocarbon concentration form the basis of many disposal regulations. In situations where the cuttings need to be treated prior to disposal, there are several possible options including cuttings re-injection, stabilization/solidification, extraction or washing, thermal desorption, landfill and bioremediation. Land farming or land spreading is a commonly used bioremediation technique in which the oily drill cuttings are applied to land where evaporation together with the natural flora and fauna of the soil combine to reduce and degrade the oil content of the waste (Zimmerman and Robert, 1991; Chaineau et al., 1996). The more complex polycyclic and aromatic hydrocarbons in the oil can be hard to degrade biologically and may persist in the soil (Growcock, 2002; Curtis, 2001). While the drill cuttings may be beneficial to the soil with the clays and lime adding structure and reducing acidity, mud systems containing calcium chloride and other soluble non biodegradable salts can also contribute to the electrical conductivity of the soil and there is the possibility of leaching and groundwater contamination. 
Cuttings discharges from offshore oil activities can cause effects that are more hazardous due to cutting contamination by oil and toxic components of drilling muds. Even after separation and cleaning in special units, drilling cuttings still contain a wide array of organic and inorganic traces especially when oilbased fluids are used. Drilling cuttings usually go overboard the offshore oil platforms in thousands and tens of thousands of tons. Hundreds of tons of oil and dozens of tons of chemical for each drilled well can enter the marine environment with these discharges. This raises serious concerns about the possible ecotoxicological disturbances in areas of offshore production.

If oil and gas exploration rigs and production installations are allowed to dump drilling wastes unchecked, the effects on marine life can be extensive and biologically significant. Over the past 40 years in the UK and Norwegian sectors of the North Sea, for example, about 1.3 million cubic metres of drill cuttings and associated wastes have built up on the seabed in 102 individual "cuttings piles" with an estimated mass of from 2 to 2.5 million tonnes. The largest pile contains over $66,000 \mathrm{~m}^{3}$ of material and weighs about 100,000 tonnes (Det Norske Veritas and Grant, 2000). The ecological effects extend for several kilometres from some platforms and can be detected up to $10 \mathrm{~km}$ from discharge points. These cuttings piles smother seabed life and remain toxic for many years, mainly because of the hydrocarbons they contain.

Oil in its many forms has become one of the necessities of modern industrial life (Moyan, 1998). Under control, and serving its intended purpose, oil is the fulcrum of industrial development. On the other hand, when oil escapes out of control it can be one of the most devastating substances in the environment. When spilled in water, it spreads for miles around leaving a black memory behind, due to its destructive nature, and once an area has been contaminated by oil, the whole character of the environment is changed. Many factors -local currents, weather, water, temperature and the composition of the oil itself, among others affect the degree of long-term environmental damage from oil spills (Maclean, 1993).

\section{METHODOLOGY}

\section{Sampling Methods:}

Five soil samples were taken at different depths and distances from polluted study area and due diligence taken to prepare them for specified tests as indicated below.

Samples for Physicochemical Analysis and Heavy Metals:

* Corresponding author: ${ }^{1}$ Joel, O. F.
About $1 \mathrm{~kg}$ soil materials were collected in plastic bags. These samples were stored in a cooler with ice blocks and transported to the laboratory.

\section{Laboratory analysis pH value determination}

About 50ml beaker was half-filled with the soil samples. Some distilled water was added to just sufficient depth to allow immersion of the electrode. Thereafter, the mixture was stirred for a few minutes. The suspension was then allowed to stand for further 15 minutes, after which the $\mathrm{pH}$ electrode was immersed into the mixture and waited for reading to stabilize. The $\mathrm{pH}$ was recorded for each sample.

\section{Electrical conductivity (EC)}

About $100 \mathrm{~g}$ of the crushed soil samples were prepared in about $25 \mathrm{ml}$ of distilled water. The electrical conductivity of the samples was determined electrometrically with a calibrated $\mathrm{HACH}$ model electrical conductivity meter. The electrical conductivity of the sample was read directly and recorded in $\mu \mathrm{S} / \mathrm{cm}$.

\section{Moisture content}

A container was dried and cooled in a desiccator and weighed. About $1 \mathrm{~g}$ grounded sample was placed in the container and the weight of both taken. The sample was dried in an air-circulation oven at $105^{\circ} \mathrm{C}$ to constant weight (at least 3hrs for $1 \mathrm{~g}$ air- dried, grounded sample). The sample and container were cooled in desiccator and weighed. The difference in weight after drying was used to calculate the moisture content.

Moisture $(\%)=\underline{\text { Loss in weight on drying }(\mathrm{g}) \times 100}$ Initial sample weight $(\mathrm{g})$

\section{Heavy metals}

A measured quantity of the samples were transferred into a Kjeldahl flask; 20ml of concentrated nitric acid $\left(\mathrm{HNO}_{3}\right)$ was added and the sample pre-digested by heating gently for 20mins. More acid was thereafter added and digestion was continued for 30-40mins. Digestion was stopped when a clear digest was obtained. The flask was cooled and the content transferred into a $50 \mathrm{ml}$ volumetric flask and made to the mark with distilled water. The resulting solution was analysed for heavy metals using the Atomic Absorption Spectrophotometer (AAS).

\section{Oil and Grease}

The soil sample was mixed using a glass rod or spatula. The samples were dried in the oven at $105^{\circ} \mathrm{C}$ to $\pm 2{ }^{\circ} \mathrm{C}$ for two hours (2Hrs). The dried material was disaggregated by gently crushing any lumps in a mortar. About $5.0 \mathrm{~g}$ of the soil sample was weighed into a $120 \mathrm{ml}$ glass bottle for extraction. $20 \mathrm{ml}$ of 
tetrachloromethane was added into the bottle containing the weighed sample and extraction done using a stirring water bath for 3hrs. The content in the glass bottle was allowed to settle and thereafter was filtered into a clean bottle using a glass funnel stuffed with cotton wool and anhydrous sodium sulphate at the aperture of the funnel. Spectrophotometer (UV) at $420 \mathrm{~nm}$ absorbance was used to determine the concentration of the oil and grease in $\mathrm{mg} / \mathrm{l}$ in the soil sample and value in $\mathrm{mg} / \mathrm{kg}$ calculated as specified below

Oil and Grease $(\mathrm{mg} / \mathrm{kg})=$

Instrument reading $(\mathrm{mg} / \mathrm{l}) \times$ solution volume $\times 10^{3}$

Sample weight $(\mathrm{g}) \times 10^{4}$

\section{Sodium Adsorption Ratio (SAR)}

The concentrations of sodium, calcium and magnesium were determined after digestion of the soil sample as described above for heavy metal determination. The solutions were then analyzed to determine the concentrations of selected ions using the Atomic Absorption Spectrophotometer. The SAR value was calculated as indicated below

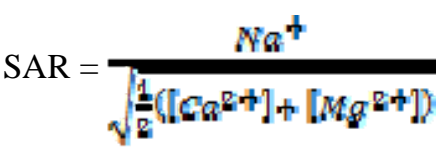

\section{Fertility test}

The soil was thoroughly wet with distilled water to a mud consistency in a conical flask. The probes of the meter were wiped clean with paper towel. The switch of the meter was moved to the first (top) position. The probes were then inserted into the soil to within 1 " of the casing. Ten seconds was allowed for the reading to stabilize. The readings were recorded, and the probes removed and cleaned thoroughly.

\section{RESULT AND DISCUSSIONS}

Table 1a: Physicochemical Analysis

\begin{tabular}{lllllll}
\hline Variable & $\mathrm{pH}$ & Temperature & EC & Moisture Content & Ammonia \\
\hline Pt. 1 & 6.9 & 27 & 21 & 40 & 2.50 & Oil and Grease \\
Pt. 2 & 6.8 & 29 & 19 & 35 & 900 & 820 \\
Pt. 3 & 6.9 & 26 & 19 & 50 & 1.50 & 220 \\
Pt. 4 & 6.95 & 26 & 18 & 50 & 1.50 & 60 \\
Pt. 5 & 6.8 & 26.5 & 21 & 56 & 2.01 & 280 \\
\hline
\end{tabular}

TABLE 1b: Statistical Analysis

\begin{tabular}{|c|c|c|c|c|}
\hline Parameter & $\operatorname{Mean}(\times)^{-}$ & Range & $\begin{array}{l}\text { Standard deviation } \\
\text { S. d. = Square root of variance } \\
\qquad \frac{\sum(x-\bar{x})^{2}}{n}\end{array}$ & DPR Limit \\
\hline $\mathrm{Ph}$ & 6.87 & 0.15 & 0.06 & $6-9$ \\
\hline Temperature $\left({ }^{\circ} \mathrm{C}\right)$ & 26.9 & 3 & 1.11 & - \\
\hline Electrical Conductivity $(\mu \mathrm{S} / \mathrm{cm})$ & 19.6 & 3 & 1.20 & - \\
\hline Moisture Content (\%) & 46.2 & 21 & 7.6 & - \\
\hline Ammonia (mg/kg) & 1.91 & 1.0 & 0.38 & - \\
\hline Oil \& Grease (mg/kg) & 456 & 840 & 338.56 & 300 \\
\hline
\end{tabular}

S. d. = Standard deviation, $x=$ variable or test result, $x=$ Mean value, $n=$ no. of plots used

Table 2a: Heavy Metal Analysis

\begin{tabular}{|c|c|c|c|c|c|c|c|c|c|c|c|c|}
\hline Variable & Iron & Copper & Chromium & Zinc & Cobalt & Nickel & Sodium & Arsenic & Lead & Cadmium & Calcium & Magnesium \\
\hline Pt. 1 & 390 & 54 & 9.80 & 13 & 0.80 & 0.09 & 0.001 & $<0.001$ & $<0.001$ & $<0.001$ & 24400 & 111 \\
\hline Pt. 2 & 550 & 23 & 6.20 & 8 & 0.22 & 0.02 & 1.90 & $<0.001$ & $<0.001$ & $<0.001$ & 17900 & 98 \\
\hline Pt. 3 & 880 & 100 & 5.30 & 10 & 0.30 & 0.32 & 1.90 & $<0.001$ & $<0.001$ & $<0.001$ & 10400 & 107 \\
\hline Pt. 4 & 1010 & 37 & 3.70 & 20 & 0.60 & 0.13 & 1.30 & $<0.001$ & $<0.001$ & $<0.001$ & 7000 & 107 \\
\hline Pt. 5 & 140 & 6 & 0.10 & 13 & 0.40 & 0.03 & 0.001 & $<0.001$ & $<0.001$ & $<0.001$ & 3100 & 81 \\
\hline
\end{tabular}


Table 2b: Statistical Analysis

\begin{tabular}{|c|c|c|c|c|}
\hline Parameter & Mean $\overline{(\times)}$ & Range & $\begin{array}{l}\text { Standard deviation } \\
\text { S. d. = Square root of } \\
\text { variance } \frac{\sum(x-\bar{x})^{2}}{n}\end{array}$ & DPR Limit \\
\hline Iron (mg/kg) & 594.00 & 870 & 317.65 & - \\
\hline Copper (mg/kg) & 44.00 & 94 & 32.16 & 36 \\
\hline Chromium (mg/kg) & 5.02 & 9.7 & 3.17 & 100 \\
\hline Zinc (mg/kg) & 12.80 & 12 & 4.07 & 140 \\
\hline Cobalt (mg/kg) & 0.46 & 0.58 & 0.21 & 20 \\
\hline Nickel (mg/kg) & 0.12 & 0.29 & 0.11 & 0.8 \\
\hline Sodium (mg/kg) & 1.02 & 1.899 & 0.86 & 35 \\
\hline Magnesium (mg/kg) & 100.8 & 30 & 10.78 & - \\
\hline Calcium (mg/kg) & 12560 & 21300 & 7665.14 & - \\
\hline Arsenic (mg/kg) & $<0.001$ & $<0.001$ & $<0.001$ & 29 \\
\hline Lead (mg/kg) & $<0.001$ & $<0.001$ & $<0.001$ & 85 \\
\hline Cadmium (mg/kg) & $<0.001$ & $<0.001$ & $<0.001$ & 0.8 \\
\hline
\end{tabular}

Table 3a: Fertility Analysis

\begin{tabular}{llll}
\hline Variable & Nitrogen & Phosphorus & Potassium \\
\hline Pt. 1 & 110 & 8.8 & 110 \\
Pt. 2 & 125 & 10 & 125 \\
Pt. 3 & 115 & 9.2 & 115 \\
P. 4 & 105 & 8.4 & 105 \\
Pt. 5 & 175 & 1.4 & 175 \\
\hline
\end{tabular}

Table 3b: Statistical Analysis

\begin{tabular}{lcccc}
\hline Parameter & Mean $(\times)$ & Range & $\begin{array}{l}\text { Standard deviation } \\
\text { S.d. = Square root of } \\
\text { variance } \sum\left(\times-\bar{x}^{2}\right.\end{array}$ & USDA Limit \\
\hline Nitrogen $(\mathrm{mg} / \mathrm{kg})$ & 126 & 70 & 25.37 & 500 \\
Phosphorus (mg/kg) & 7.56 & 8.6 & 3.13 & 40 \\
\hline Potassium (mg/kg) & 126 & 70 & 22.36 & 500 \\
\hline
\end{tabular}

PT. 1: Surface sample from polluted area

PT. 2: 20ft away from polluted area

PT. 3: 1Foot depth from polluted area

PT. 4: $2 \mathrm{ft}$ depth from polluted area

PT. 5: 30meters away from polluted area

Among the heavy metals tested, chromium, zinc, cobalt, cadmium, nickel and arsenic were within acceptable limit (Table 2b) as specified by DPR and do not pose a concern. However, the concentration of copper and iron were very high and above specified target value by DPR. As a result of percolation, sample from deeper depth indicated higher iron contamination, and this increased as the depth increases. Previous work showed that percolation and run-off of effluents into ground and surface waters could render the soil unproductive. Moreover, heavy metals such as arsenic, lead, cadmium and chromium can accumulate in the soil, resulting to contamination of the soil. These heavy metals can accumulate in our body when we eat food made of these plants thereby causing poisoning (Mueller Associate Inc, 1987).

Test result (Table 1a) indicated that the oil and grease on the surface and 20 feet around the waste dumped area were above the specified limit. Values at 1 foot deep and 30meters away from the polluted area also gave an indication of contamination due to percolation and dispersion. Previous research has shown that the mechanism of transmission in the soil is basically by leaching via percolation. By this process, contaminants are dissolved and carried away by water or moved into a lower layer of soil by

* Corresponding author: ${ }^{1}$ Joel, O. F. 
seepage under the forces of gravity through a porous substance. The contaminants can also migrate by percolation through the soil by direct run-off, volatilization and by dust transport. (Eilberk and Mattock, 1987).

Test results (Table 3a) indicated that the NPK values were far below the values specified by USDA STANDARD for plant growth. The unproductive nature of the soil could be attributed to higher percentage of hydrocarbon content along with residual salt from the internal phase of the drilling cuttings.

Conclusion: The waste dumped in the area contained some hazardous pollutants which polluted the land and affected plant growth. The pollution was not only noticed at the surface but also at the subsurface. When drilling cuttings are disposed indiscriminately, the negative impact to the environment could be alarming. Therefore, government should develop stringent disposal regulations to prevent this wholesome attitude of oil operators. Due diligence in restoring polluted sites to base-line level should be emphasized.

\section{REFERNCES}

Drilling Fluids Engineering Manual, M-I L L C (1998).

Growcock F B (2002). "Designing Invert Drilling Fluids to Yield Environmentally Friendly Drilled Cuttings,” SPE 74474, IADC/SPE Drilling Conference, Dallas, Texas, USA (February 2628, 2002).
Curtis G W (2001). "Can Synthetic Based Muds Be Designed to Enhance Soil Quality?” AADE National Drilling Conference on 'Drilling Technology', Houston, Texas, USA (March 2729, 2001).

Zimmerman P K and Robert J D (1991). "Oil-Based Drill Cuttings Treated by Landfarming,” Oil and Gas Journal, 81 (1991).

Chaineau C.H., Morel J.L. and Oudot J., "Land Treatment of Oil Based Drill Cuttings in an Agricultural Soil,” J. Environ. Qual., 25, 858867 (1996).

Det Norske Veritas and Grant, A (2000). Toxicity and Environmental Risk Assessment of Drill Cuttings Piles. University of East Anglia, Norwich).

Maclean, H (1993). Manchester Guardian Weekly Social Issues Resources Series 5(61) pp 18 - 20.

Moyan, A (1998). Oil Spill Response. Interdisciplinary Minor in Global Sustainability, University of California Irvine, pp. 1-5.

Mueller Associates Inc. (1987). Waste Oil Reclaiming Technology, Utilization and Disposal, Pollution Control Review No. 166, Baltimore, Maryland, pp 41-48.

Eilbeck, W J; Mattock, G (1987). Chemical Process in Waste Water Treatment, Environmental Association LTD, New York, pp 13-28, 232, 312. 